\title{
Motorized Tripod for Smartphones
}

\author{
D.Sharmitha J. Jeffrin
}

\begin{abstract}
Press people attend technical events and other recreational events for covering the happenings of the event. Also, during functions in educational institutions and similar places, it involves live streaming of those events on social Medias. Smartphones help a lot in streaming these events live on social Medias. Often this live coverage is shaky and results in poor quality of the coverage. Hence, a portable motorized tripod with controller for smartphones is proposed. The smartphone is mounted on the tripod. The tripod consists of few predefined motion patterns, which can be enabled through controller on an app. The app is installed on a phone and then the tripod relates to the phone through Bluetooth. Thus, this product will enable the user to record and stream live without shake and the motion pattern will provide a standard video output. Apart from the motion patterns, the position of the smartphone can be changed as per the user needs using the app.
\end{abstract}

Keywords: Smartphone, tripod, switch, control, social media, Bluetooth

\section{INTRODUCTION}

Motorised Precision is a company that manufactures motorised arm like structures which provide provision for handling high end cameras, mounted over them for more dramatic video shots. This robotic arm is costly and has provision for mounting only certain range of cameras. This high-end technology can be incorporated into daily smartphone users, because smartphones have several apps installed in them which can record dramatic shots, stream live and have OIS and EIS built in and, this becomes the idea of this project.

\section{Problem Statement}

While telecasting live content on to social medias, it can be difficult to produce smooth video output using smartphones, when handheld. Thus, it results in poor quality of the coverage of live event. Also, if an external camera is used to telecast the event, additional computers and software is required to telecast the recorded content on to social medias. This is overcome by our idea, "Motorized Tripod for Smartphones". This product can also be extended for use in recording videos for recreational purposes.

This project involves in designing the prototype of a product for use in real life practical applications. This product comes under the field of "Automation using Embedded Systems". Arduino is used here to control motors. The stepper motors used here are interfaced with Arduino and controlled through a motor driver. The pattern of motion of these stepper motors depend on inputs from the controller app through Bluetooth.

Objectives:

Revised Manuscript Received on August 14, 2019.

D.Sharmitha, Assistant professor, Department of EEE, Kumaraguru College of Technology, Coimbatore, T.N, India. (Email: sharmitha.d.eee@kct.ac.in)

J. Jeffrin, Student, Department of EEE, Kumaraguru College of Technology, Coimbatore, T.N,India. (Email: jeffrin.15ee@kct.ac.in)
$>$ To develop a prototype of the motorized tripod which can be used to control the position of the mounted smartphone.

$>$ Both vertical and horizontal axis control stepper motors are interfaced with the Arduino.

$>$ Controlling the tripod through app using Bluetooth.

Several methods are proposed for stepper motor control. [1] explains automatic rising and falling speed control method of stepper motor using Lab VIEW. [2] presented speed control of stepper using AT89S51 Microcontroller. [3] representsed the study of open-loop control of stepper motor using Microcontroller Unit (MCU) for optimizing the motion flexibility and precision. The proposed system describes on Arduino based acceleration and deceleration control of stepper motor for tripod application using smartphones.

This paper is organized as follows. Section 1 describes with the problem identification and objectives of the project. Section 2 deals with the proposed system configuration and overall structure of the project. Section 3 focuses on the implementation of the system. Section 4 presents the hardware results. Section 5 points the conclusion of the project results and future scope.

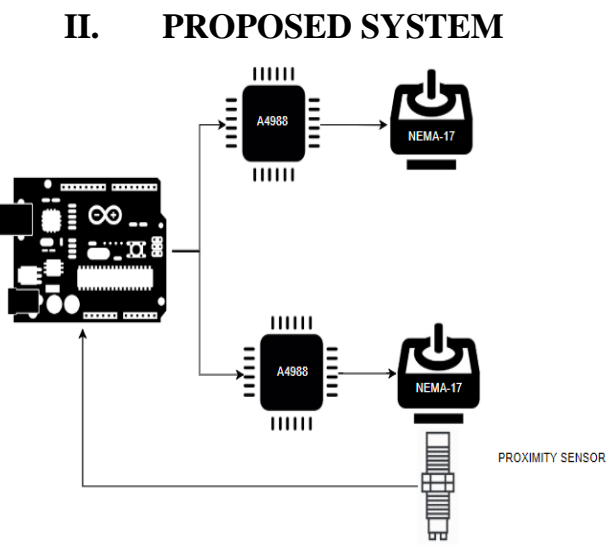

Fig-1 Configuration of Components

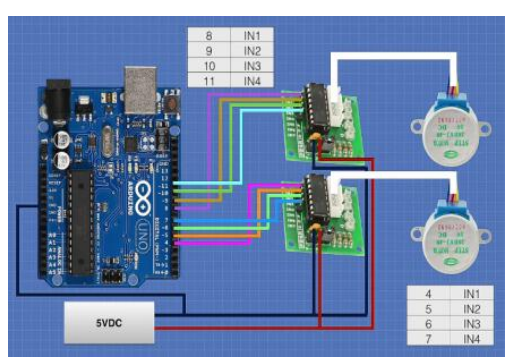

Fig-2 System Implementation

Published By:

Blue Eyes Intelligence Engineering \& Sciences Publication 


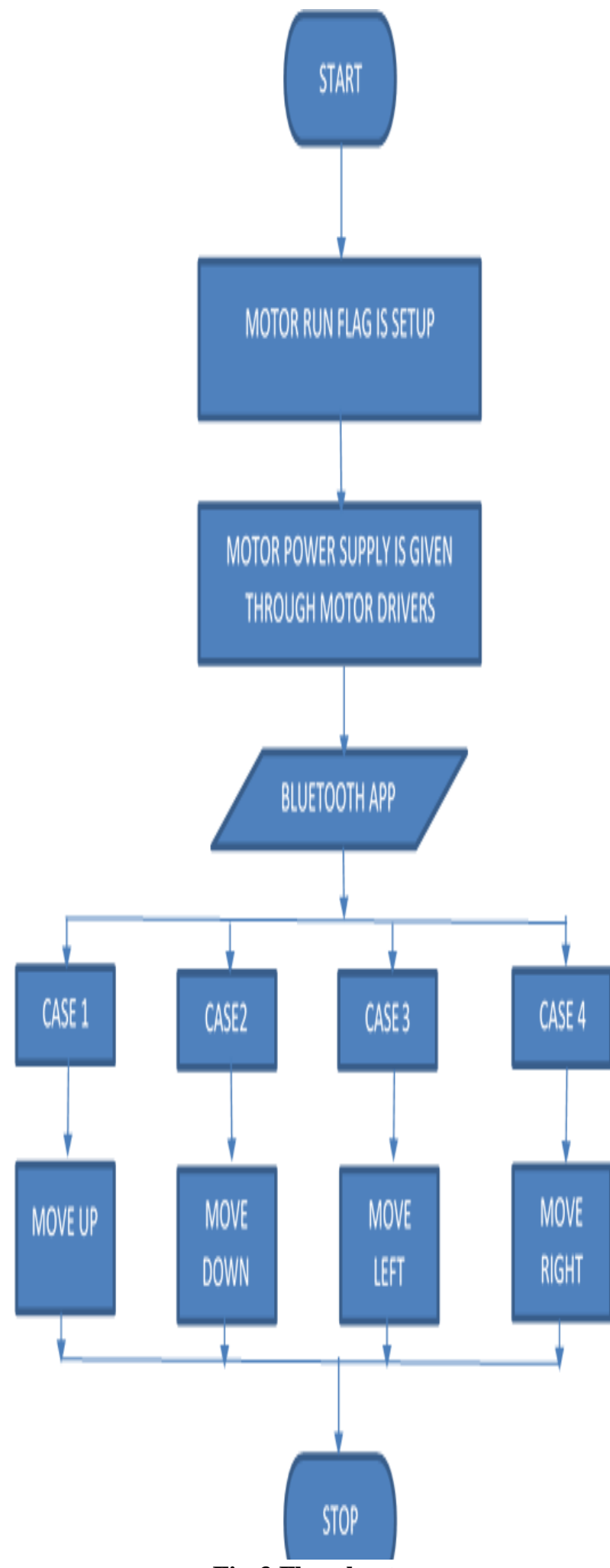

Fig-3 Flowchart.

The system structure represents the connection of the individual components. There are two stepper motors. They are used for producing both vertical and horizontal movement required for the tripod. The stepper motors used here are of $4.3 \mathrm{Kg} \mathrm{cm}$ torque and a rated current and voltage of 2 Amps and 12 Volts respectively.

The motor driver is connected to the Arduino. This motor driver drives the stepper motor depending upon on the required pattern. The motor driver used here is A4988.

The required power supply of 12 Volts is provided to the Arduino and to the motor driver. The stepper motor is not provided with power supply directly. This power supply is regulated by using the motor driver. The following Fig 2 . showcases the implemented circuit diagram of the system.

\section{FLOWCHART FOR STEPPER MOTOR CONTROL.}

The following Fig 3 describes the flowchart followed to control the stepper motors using the A4988 motor driver. This gives an overview on how the implementation is proceeded.

\section{IMPLEMENTATION OF THE SYSTEM}

The required connections are made between the Arduino Uno, NEMA 17 Stepper motor, Inductive proximity sensor and the A4988N Motor Driver. The program required to drive the stepper motor is written and then dumped into the Arduino Uno using the Arduino IDE software.

The metal frame is made ready for mounting the components on them. Once the metal frame is ready, both the NEMA 17 Stepper motors are mounted on to the frame. The rack and pinion are also fitted into the frame. Also, the smartphone holder is mounted over the stepper motor. Thus, the tripod can now move the smartphone.

On powering the tripod, the Bluetooth module gets activated. Now an Android smartphone is connected with this Bluetooth and the control app is now opened, using which the tripod can be controlled.

Initially, we used the $\mathrm{L} 298 \mathrm{~N}$ motor driver to control the stepper motor. But the heat output of the motor driver was so high even under less load. Hence, we switched to the A4988N motor driver. This driver is capable of withstanding high current even during load. Thus, the heat output was reduced. But the downside of using this stepper motor driver was that it was not easy to interface with Arduino. In other words, there are no native header file for easily programming the stepper motor control.

\section{HARDWARE RESULTS}

The stepper motors used here are rated for 12 Volts DC power supply. And hence, the required voltage supply is provided through RPS. The output of the RPS terminals are connected to the power supply rails provided in the breadboard. Then, from the power rails, the Arduino Uno is grounded. Also, the two motor drivers require a positive and negative terminal which can be connected to power rails. The stepper motors receive the required power supply from the motor drivers. The Arduino Uno is connected to the USB terminal for powering itself. Fig 4.1 shows the hardware prototype made.

The rack and pinion structure we have used are made of synthetic fiber. And hence the gear teeth are not perfectly shaped don't move correctly. And hence we were able to make the smartphone move from top to bottom but not vice versa. Initially, it was thought that this motion was not working because the stepper motor didn't have enough

Published By:

Blue Eyes Intelligence Engineering \& Sciences Publication

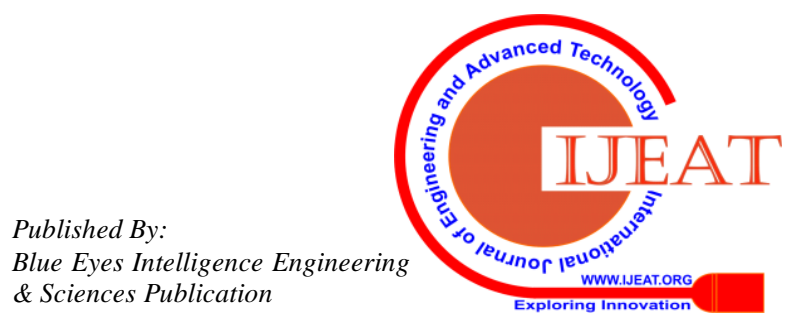


torque to push the structure upwards.

So, in order to check it out, we bought a new NEMA 23 stepper motor which has a rated torque of $10.3 \mathrm{Kg} \mathrm{cm}$. Even when this motor was used, the motor was not able to move the structure up. This made us conclude that, the rack and pinion which was made of synthetic fiber has some irregular gear teeth which makes the upward motion difficult to achieve.

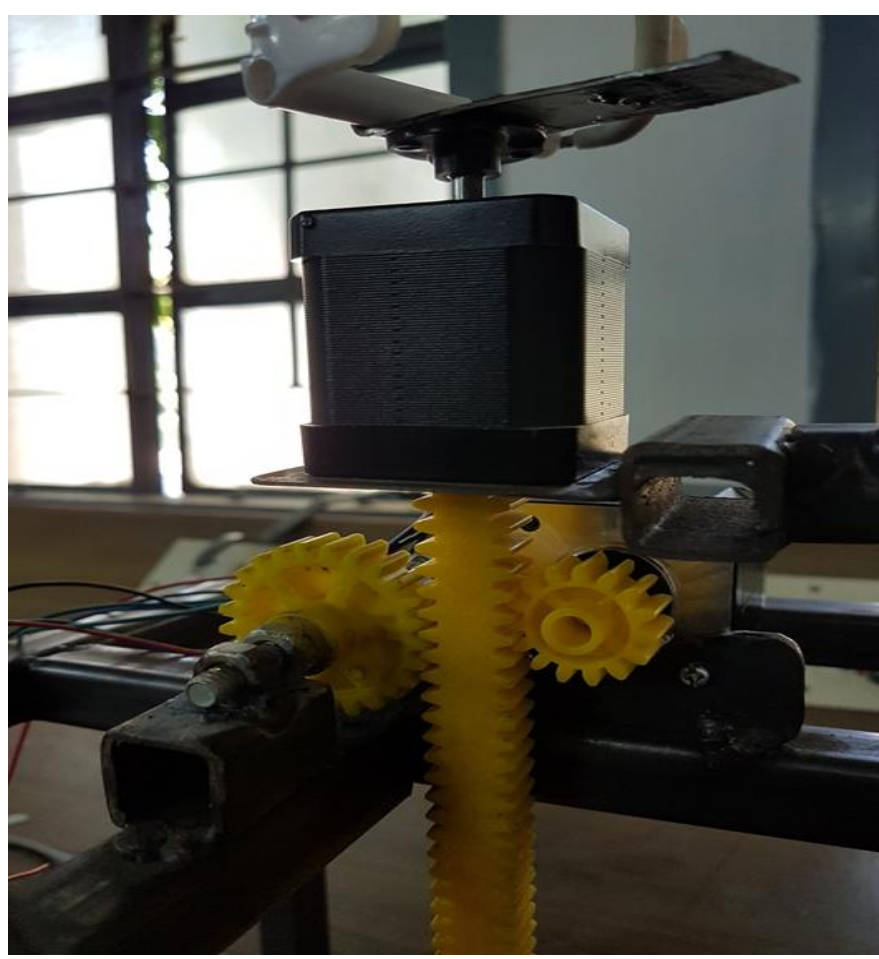

Fig-2 Rack and Pinion arrangement.

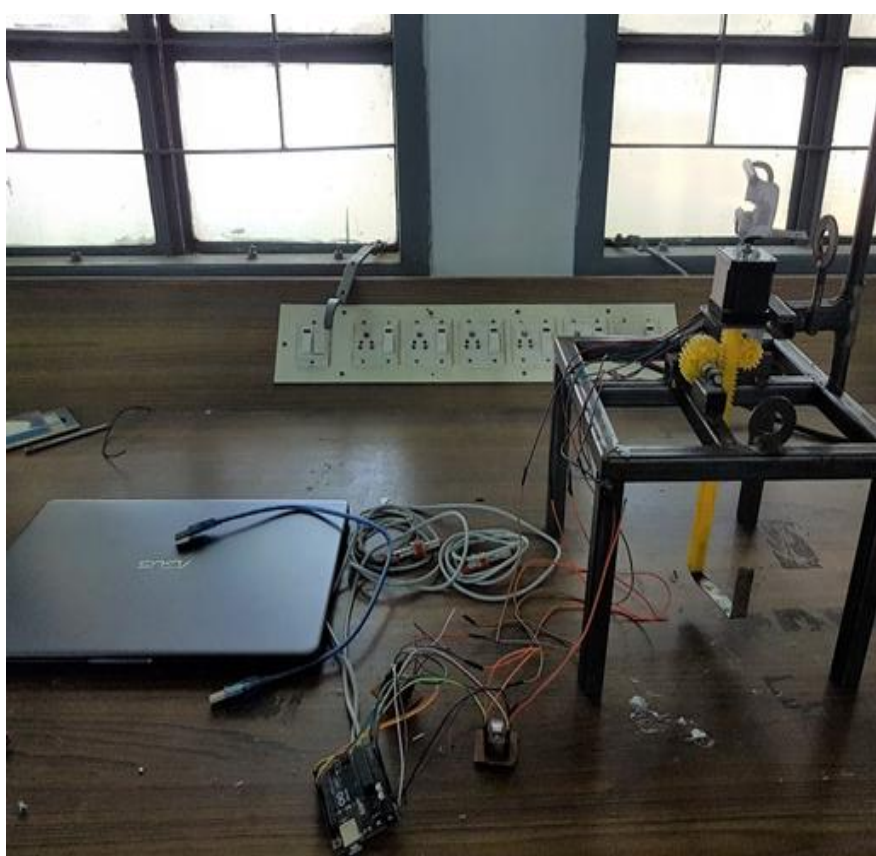

Fig-2. Hardware Output

For Bluetooth control, we installed the Arduino Bluetooth Controller App from the Google Play Store on a smartphone. Once it is installed, the Bluetooth Module is interfaced with Arduino Uno. The RX and TX pins are connected with the Arduino TX and RX pins respectively. Also, the power supply is given from the 5 Volts port and
Ground on the Arduino. The app is then paired with the Bluetooth module and upon pairing, the serial input values which are required are set in the controller of the app. This enables controlling the tripod from the smartphone. If you are an iOS user, there is an app called "Handy Bluetooth Arduino Controller" from Paul Shelly on the Apple iTunes Store, which works like the android app.

\begin{tabular}{|c|c|c|}
\hline Component & $\begin{array}{c}\text { Current drawn } \\
\text { under no load }\end{array}$ & $\begin{array}{c}\text { Voltage } \\
\text { supplied }\end{array}$ \\
\hline Stepper Motor \#1 & $1.7 \mathrm{~A}$ & $12 \mathrm{~V}$ \\
\hline Stepper Motor \#2 & $1.5 \mathrm{~A}$ & $12 \mathrm{~V}$ \\
\hline
\end{tabular}

Table-1. Stepper motor Specification

\begin{tabular}{|c|c|}
\hline Description & Value \\
\hline $\begin{array}{c}\text { Step Angle of both Stepper } \\
\text { Motors }\end{array}$ & 1.8 Degrees \\
\hline Total steps per revolution made & 200 Steps \\
\hline Total Voltage Supplied & 12 Volts \\
\hline Voltage across motor terminals & $\sim 5.5$ Volts \\
\hline
\end{tabular}

Table-2. Component Description

\section{CONCLUSION \& FUTURE SCOPE}

Thus "Motorized Tripod for Smartphones" has been designed and most of the scope objectives of the project are obtained. Two NEMA 17 stepper motors are controlled with two A4988N motor drivers and interfaced with the microcontroller of choice, Arduino Uno.

Different pattern of movements is produced by using both the stepper motors which can be selected by the app on an Android smartphone.

\section{Future Scope:}

The main downside we faced during the development of this project is that the upward motion of the tripod was not working. The main factor which caused this error was the usage of synthetic fiber rack and pinion. Using a rack and pinion made from metal will be more accurate in terms on motion as we might see in everyday industrial applications. So, by using rack and pinion made from metal can be used in future models to overcome this error. This product finds application in:

- Live video streaming

- Recreational purposes

Also, this product can be further improved by incorporating a Power Bank with the tripod for the smartphone being used with the tripod, because during live streaming conditions, battery usage of the smartphone will be high, as the smartphone will be simultaneously recording the video content and uploading that content to the internet.

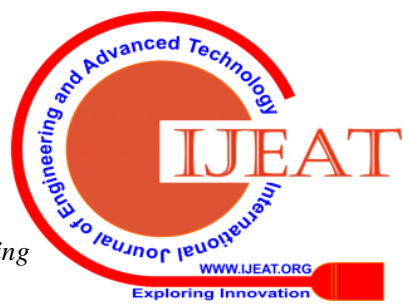




\section{REFERENCES}

1. Shuqiu Gong and Bin, "LabVIEW-base automatic rising and falling speed control of stepper motor", International Conference on Electrical Machines and Systems, 2009.

2. Wang Ruifeng, Wang Zhe and Wang Liying, "Stepper Motor Control Based on AT89S51 Microcontroller", 2015 8th International Conference on Intelligent Computation Technology and Automation (ICICTA), 2015

3. Lili Zhang, Li Liu, Jing Shen, Jiahui Lai, Kesen Wu, Zhao Zhang and Jian Liu, "Research on stepper motor motion control based on MCU”, 2017 Chinese Automation Congress (CAC), 2017. 